\title{
On Foreignization of Cultural Elements in the Translation of Classical Chinese Poetry
}

\author{
Hongwei Ye \\ School of Fundamental Studies, Shanghai University of Engineering Science, Shanghai, China
}

\begin{abstract}
Based on the theory of foreignization and domestication, this essay analyzes the translation of cultural elements in classical Chinese poetry (CCP) and advocates that foreignization should be employed as the preferable approach in the translation of the cultural elements with Chinese cultural connotations.
\end{abstract}

Index Terms-foreignization, cultural elements, classical Chinese poetry

\section{Cultural Translation Strategies: Domestication and Foreignization}

Translation is a cross-cultural practice, so how to deal with the cultural elements in literary translation has long been a heated topic for debate. Generally speaking, there are two strategies in dealing with cultural elements: foreignization and domestication. The roots of these two terms can be traced back to the German theologian and philosophers Friedrich Scheiermacher's lecture "On the Different Ways of Translating" in 1813. In this lecture, when he talked about the different methods of translating, he said that there are only two different methods of translation: "either the translator leaves the author in peace, as much as possible, and moves the reader towards him; or he leaves the reader in peace, as much as possible, and moves the author towards him" (Venuti, 2004, p.19-20). In his book The Translator's Invisibility in 1995, Lawrence Venuti coined two terms to describe these two methods: domesticating translation and foreignizing translation. The former refers to "the type of translation in which a TT is produced which deliberately breaks target conventions by retaining something of the foreignness of the original." (Shuttleworth. M \& Cowie. M, 2004, p.59) The later, however, is "the translation strategy in which a transparent, fluent style is adopted in order to minimize the strangeness of the foreign text for TL readers" (ibid,p.43-44).

\section{A. Nida's Advocacy of Domesticating Translation}

Domestication-oriented translation in the West started in Britain in the 17th century. There have been many advocates of domestication in the circle of translation, such as Delhram, John Dryden, and Tytler. By putting forward his "dynamic equivalence" theory, Eugene. Nida, the American translation theorist, made himself the theoretic representative of domestication school.

He defines the ideal of translation as "the reproduction in a receptor language of the closest natural equivalent of the source language message, first in terms of meaning, and second in terms of style". (Nida, 2004, p.210) He puts forward the concept of "Dynamic Equivalence (or Functional Equivalence)"that "aims at complete naturalness of expression and tries to relate the receptor to modes of behavior relevant within the context of his own culture (ibid, p.159). Nida lays much emphasis on the reader's response, so in his opinion, the translator's way of expressing should be completely natural and in the translated text, the original cultural elements should be embedded into the TL reader's culture category.

It is obvious that, the process of achieving "naturalness of expression" involves domesticating translation. In a recent work, Nida states (2004, p.56) "the translator must be a person who draws aside the curtains of linguistic and cultural difference so that people may see clearly the relevance of the original message." So according to him, domestication is not only necessary but also unavoidable and translators must overcome the barrier of the language as well as the culture so as to help the TL readers better understand the SL. Thus, the English expression "to grow like mushrooms" can very well be translated into Chinese as “雨后春笋” because Chinese readers will have the similar associations to those of English readers and thus the dynamic equivalence is achieved. By making such change of cultural images in translation, Nida holds that cultural conflicts can be avoided. Obviously, Nida lays more stress on the retention of meaning than that of cultural essence, which is consistent with his principle of translation, that is, translating is translating meaning.

Domestication has long been the dominant school of translation in the West. Venuti points out that "English translation has taken, ever since the 17th century, 'fluent translation'-domestication, as its dominant stream and it has be continued till the present day." (2004, p.66) Nida and those who advocates domestication have roughly three reasons:

First, the SL and TL have different linguistic and cultural norms; it is not only hazardous but also unrealistic to force one into the pattern of another. A good translation should overcome the linguistic as well as cultural barriers to ensure the readability and understandability of the translated text.

Secondly, the intended reader and his expectation should be the greatest concerns of the translator. The Reception Theory indicates that the comprehension of the text is based not only on reader's linguistic knowledge but also on his 
prior knowledge of the world, so the cultural barriers that hamper the reader's understanding of the text should be modified in order to fulfill the function of communication.

Finally, in meeting the needs of cultural contact and intercultural communication, a translator should avoid cultural conflicts that may lead to cultural misunderstanding. A domesticating translation brings about content and forms familiar to the TL readers, thus achieving high degree of effectiveness.

The domesticating translation tends to bring out the communicative aspect of language and translation and is easier for the readers to understand and accept. It has been very powerful and popular for a long period in translation circle. However, the naturalness and easiness of the target text are often achieved at the expanse of cultural messages of the source text. The direct result of this kind of translation is more or less a degree of "normalization", where all the otherness of the source language culture is made to disappear. With the development of cultural exchanges, domestication can no longer meet the needs of readers who are eager to know more directly and authentically foreign cultures. Therefore, translators turn to the other strategy-foreignization.

\section{B. Venuti's Advocacy of Foreignization Translation}

Foreignization, quite opposite to domestication, is source language culture-oriented in handling the cultural elements in translation. Although there have been lots of scholars who advocates foreignization, such as Friedrich Schleiermacher, Walter Benjamin and Antoine Berman, it is Lawrence Venuti who make the greatest contribution to the development of this strategy.

In western translation history, what prevailed was traditional fluent strategy -domestication, which seeks an illusion of transparent translation. People like Venuti maintain that the illusion of transparency, the effect of fluent strategy, makes the translator invisible and the translated text "natural". After criticizing the dominating domestication method, Venuti advocates foreignized translation in order to "develop a theory and practice of translation that resists dominant target-language cultural values so as to signify the linguistic and cultural difference of the foreign text" (2004, p.23)He regards the domestication as cultural narcissism and imperialism. And the purpose of foreignization, according to him, is to resist against the ethnocentrism and racism.

Lawrence Venuti, an affirmative advocate of foreignization, is most well known for his concept of "resistant translation", according to which the foreignness of the source-language text should be kept obvious in the target-language text. He overtly states that his purpose is to develop a new type of translation theory and practice, to stop the target-language culture from taking the leading position. He even goes so far as to oppose the smoothness of target-language text.

Foreignization aims to transmit the alien features of the source culture, transplanting the new images and concepts into the target language and culture. Thus the target language will be enriched and reformed. Venuti holds that domesticating translation makes the translator invisible and the dominant cultures usually adopt the domesticating translation strategy to produce coherent reading for the target language readers. On the surface, the translated text reads fluently and naturally but source language culture is effaced. He calls this "cultural imperialism" and advocates that American translators employ the resistant strategy-foreignizing translation to resist cultural hegemonism. He holds that it is the translator's responsibility to show the linguistic and cultural differences in translation rather than efface them.

\section{Different Methods OF Foreignizing Translation}

The translator plays an important role in establishing cultural equivalence between the source text and the target text. Whether or how to establish cultural equivalence in translating the cultural elements depends on many elements, among which the cultural flavor of the source text is the most important. In other words, translators should employ foreignization strategy to keep the original cultural messages to a high degree so as to fulfill the task of cross-cultural communication. However, strategy is a general direction or planning. It is different from method and technique. Strategy means a general decision at a higher level, while method and technique are used to mean the specific way of doing or performing something. They are, literal translation, literal translation with cultural compensation, and transliteration, which are obviously under the category of foreignizing translation.

Of course, these translation methods can be combined and in fact are combined, and there is nothing strange for the same translator to use different methods in treating identical potential cultural elements in CCP. Different methods are illustrated through examples of English translation of CCP, which can, if not fully, at least to some degree, show the possibility and effect of foreignizing translation.

\section{A. Literal Translation}

Literal translation refers to the translation of the cultural terms according to their literal forms. It is the form of foreignization that is used by translators most frequently. This method is one of the most important means to introduce the SL culture into TL culture because it does little violence to the source language, therefore, the natural flavor of source language culture, i.e. the exotic expressing form or unique foreign cultural images can be retained in the translated versions. "In the case of minor literature that is closely bound to its period and its culture, semantic translation will attempt to preserve its local flavor" (Newmark, 2001, p.45). Here, the so-called "semantic translation" 
by Newmark is similar to literal translation to some extent. "In literary translation, the foreignization of cultural elements implies that literal translation (including transliteration) should be the main method." (Zhang Junfeng, 2004, p.2) By using literal translation we can increase the informativeness of the cultural meaning transferred from the SL text to the TL text. In addition, literal translation is the most effective way of enriching TL and its culture.

As cultural elements in CCP are closely bound to the special period and unique Chinese culture, in order to maintain the Chinese cultural features, literal translation should be practiced as much as possible. For example:

Original: 美人卷珠宋, 深坐蹙蛾眉。

但见泪痕湿, 不知心恨谁。(李白《怨情》)

Version 1: A fair girls draws the blind aside.

And sadly sits with drooping head;

I see her burning tear-drops glide

But how not why those tears are shed. (Tr. Herbert A. Giles)

Version 2: My lady has rolled up the curtains of pearl,

And sits with a frown on her eyebrows apart.

Wet traces of tears can be seen as they curl.

But who knows for whom is the grief in her heart? (Tr. W.J.B.Fletcher)

Version 3: A lovely woman rolls up the delicate bamboo blind.

She sits deep within, twitching her moth eyebrows.

Who may it be that grieves her heart?

On her face one sees only the wet traces of tears. (Tr. S.Obata)

“蛾眉” is a characteristic image in Chinese culture. It literally refers to the thin, curved and delicate eyebrows; they are regarded as beautiful eyebrows in Chinese. Poets frequently used this image to describe the appearance of women: 六军不发无奈何, 宛转蛾眉马前死 (白居易《长恨歌》) ; 却嫌脂粉污颜色, 淡扫蛾眉朝至尊。(张祜《集灵台 之二》); 禅心一任蛾眉妒，佛说原来怨是亲。(苏曼殊: 《寄调筝 人三首·之一》) In each line, the phrase “蛾 眉”depicts a beautiful young lady in front of us when we read them. It has even become a metonymy of beautiful young lady in Chinese culture. In the original poem, “蹙蛾眉”describes vividly the appearance of the beauty and the sad mood and to a great extent activates the readers' imagination. It produces two images and gives expression to a high level of artistic conception. In Version 1, Giles just put it into "head”, and according to his version, “咸蛾眉” was changed into “低垂着头”. This essential image was lost, so was the meaning of the poem changed. In version 2 Fletcher translate “蛾 眉” into "a frown on her eyebrows" without preserving the word "moth", which is crucial in the description of a beauty. Obata is most successful from the aspect of keeping the original cultural flavor. By literal translation of “蛾眉”, he not only retains the artistic image of the original, but also introduces an new expressions to target language readers, leaving them space of imagination.

\section{B. Literal Translation plus Cultural Compensation}

There are some Chinese cultural elements that are not intelligible to the people of English culture, so complete literal translation is not able to convey the original meaning or even may arouse misunderstandings of the source culture, then some compensations are needed to retain the flavor and exact meaning of the original. "The compensation in translation is to make up the semantic losses caused in the cause of converting the linguistic forms of the original language into those of the target." (Liu Chongde, 1991, p.131) It is an indispensable method to overcome the difficulties in the translation of literary, especially poetic works. This method is used to make explicit the meanings of culture-specific expressions that puzzle the TL reader. When the cultural background information is necessary for the TL reader to achieve the coherent meaning of the original is not too much, we can often use this cultural compensation. Literal translation together plus some contextual explanation can provide the necessary cultural background of source language so as to help the target reader understand and accept the source cultural information sufficiently. Although the translated versions may seem strange and lengthy at the first sight, but with the passage of time or the frequent use, these cultural terms enter the target culture and become familiar to the target readers, and may be used as common words by target language writers. And in this case, the explanatory notes that are tagged after the literal translation can be removed then. In the translation of $\mathrm{CCP}$, for some cultural elements with particular local color with which the Western readers may have some difficulty in appreciating, this method is particularly suitable. It can faithfully preserve the Chinese culture flavor, and at the same time reduces the degree of misreading or misunderstanding, which can be demonstrated by the following example.

Original: 庄生晓梦迷蝴蝶, 望帝春心托杜鹃。(李商隐 《锦瑟》)

Version 1: Zhuang Zi got mixed up in his dream with a butterfly.

Emperor Wang consigned his amorous heart in spring to the cuckoo. (Tr. James J. Y. Liu)

Version 2: Puzzles as felt by Zhuang Zhou from his dream of butterfly;

Sadness as aired out by King Wang's soul in cuckoos cry. (Tr. Zeng Bingheng)

Li Shang-yin was the first and most important symbolist poet in China, who was much admired for his complex, allusive style and wistful, often romantic subject matter. “庄生晓梦迷蝴蝶” in this poem is from $\mathrm{Zhuang} \mathrm{Zi}$ (《庄子》): 
“昔者庄周梦为蝴蝶......不知周之梦为蝴蝶与, 蝴蝶之梦为周与?” Zhuang Zi dreamed of a butterfly, but he could not make out whether he had dreamed of the butterfly or the butterfly had dreamed of him. Li Shangyin borrowed this to express his puzzle when he was deep in the recalling of the past: whether he was living in the past at present. The allusion in “望帝春心托杜鹃” is from a Chinese Classic work-《寰宇记》: “蜀王杜宇, 号望帝, 后因禅位，自亡去， 化为子规。” Here “子规” just refers to “杜鹃”, by which the poet expresses his sadness that his grief could only be reposed to the cry of cuckoos.

In Chinese culture, “杜鹃” symbolizes sorrowfulness, whereas in western culture it is associated with happy feelings. In the first version, the translator is not aware of the difference and the method of literal translation is used here. It makes readers know only the surface meaning but not the deep cultural senses they carry. This translation distorts the original and causes the western reader to think that Emperor Wang has a happy love affair. The second version expresses the meaning of the original more faithfully through adding "cry" and makes the readers understand the connotative meaning of this animal image. Thus, the translation achieves the aim of keeping the cultural image without causing misunderstanding and introducing the cultural connotations of cuckoo in Chinese to TL readers.

\section{Transliteration}

Transliteration is a kind of method, which keeps the pronunciation or spelling of the SL cultural item and the major function of designative meaning in the translated versions. Transliteration is one type of phonological correspondences between SL and TL. It is also a method to borrow some lexical units from SL, so transliteration is sometimes called borrowing. In the case of cultural default only transliteration and borrowing can transfer almost the whole cultural message of the SL text to the TL text. Transliteration cannot only make the translated text concise, but more importantly, it can avoid the cultural default caused by free translation so as to achieve semantic equivalence in SL culture and TL culture. Transliterated words may also add freshness and vitality to target language and enrich its expressions.

This method is often used in translating some proper names, especially names of persons, places or geographical features, or objects, things and phenomenon peculiar to the source language culture that have no correspondences in target language culture. Proper names peculiar to the SL culture can only be transliterated and left intact. Terms of these kinds in CCP are usually considered as untranslatable, but through transliteration, not only can the cultural message be reserved, but also propose the target readers a new insight into Chinese culture. Let's study the translation of the following poem:

Original: 江南好, 风景旧曾谙。(白居易《忆江南》)

Version 1: Fair southern shore

With scenes I much adore.(Tr. Chen Gang)

Version 2: How deeply I appreciated

The beauty of Jiangnan!( Tr. Rewi Alley)

Jiangnan is a constantly quoted proper name in Chinese poets' works like:正是江南好风景, 落花时节又逢君。 (《江南逢李龟年》); 闲梦江南梅熟日, 夜船吹笛雨萧萧。(皇甫松《梦江南》); 人人尽说江南好, 游人只合江南 老。(韦庄的《菩萨蛮.人人尽说江南好》) Through the ages, Jiangnan has been the wealthiest region in China, producing first-rate rice, silk and tea leaves. Jiangnan is famed for its scenic water towns and lakes. These poems give full description of the natural beauty of Jiagnan. Literally, it means the south of the Yangzi River, but its association goes far beyond this literal meaning. It can be associated with prosperity, beautiful spring or nostalgic feelings. This poem written by Bai Juyi is one of the most famous among all the poems about Jiangnan. In Version 1, “江南”was literarily translated into "southern shore", with all the beautiful associations lost. In Version 2, by transliterating it, the translator avoids making the implied connotation explicit but requires readers to spend more efforts finding out the associations. Since this cultural element is very important, the translator considers it justified for readers to familiarize themselves with the background knowledge so as to obtain more about Chinese "Jiangnan" culture. Other proper names like “塞北” (beyond the Great Wall), “辽西” (region to the west of the Liaohe River), “秦淮” (Region around the Qinghuai River) and “扬州” (city of Jiangsu Province), and animal names like “麒麟” (an auspicious legendary animal with a horn and scales all over) are also full of cultural connotations which may arouse imaginations from anyone who knows about ancient Chinese history and geography, which should all be preserved in the translated poem.

Through transliteration a lot of borrowed cultural terms have been gradually adopted by receptor languages, thus enriching the communicative aspect of the receptor culture. The loan words, transferred words or adopted words in all languages are usually introduced through transliteration. Thanks to the adoption of transliteration, we can find lots of Chinese cultural terms in the English vocabulary, such as Yin and Yang, Kungfu, Kowtow, Taiji and Taoism, which have found their way to the English dictionary and therefore become formal vocabulary and part of the western culture. In brief, transliteration is an effective way for retaining the original cultural message and enriching TL culture.

\section{DOMESTICATION AS A SUPPLEMENTARY STRATEGy to ForeignIZATION}

The language of a nation always expresses its particular culture in the area, and different countries have different cultures. As mentioned above, many Chinese cultural expressions can be directly foreignized into English. But there are still quite a number of them that can't be foreignized, otherwise, the faithful principle will be broken and the original 
meaning cannot be kept in the target text, in this case, the only way out is to use domestication as a supplementary strategy. Some poetry contains some cultural elements with strong cultural connotations: and these connotations can hardly be understood if the translator tries to retain the alien cultural terms in the translated version. In this case, if the translator insists on foreigniztiaon, it will not only fail to transmit the SL culture to TL but also fail to achieve the communication effects. Therefore, a wise translator, in this case should consider sacrificing some cultural images and focus on the communication of the connotative meaning of the cultural elements.

However, domestication should not be used as the dominant cultural strategy for the translation of cultural elements in CCP. In an age when different cultures confront the tendency of being globalized, the translation of CCP should be more foreignized so as to contribute to the promotion of the communication between different cultures. It is under such conditions that a translator should adopt foreignization wherever possible and employ domestication when necessary in the process of translating cultural elements of CCP into English. In fact, the relation between domestication and foreignization is not contradictory. Advocating one strategy doesn't necessarily mean depreciating the other. To emphasize foreignizing translation is not to exclude domesticating translation since acceptability of the target text should also be taken into consideration. The way out is to keep the cultural connotation of the source text to such a degree that the foreignizing translation can be still acceptable.

\section{CONCLUSION}

In conclusion, foreignization is an effective strategy in cultural transfer. It can introduce foreign cultures to the readers to enrich their knowledge and broaden their field of vision. However, it is impossible for a translator to use foreignization only. There are always some elements that are difficult to translate by foreignization. If a translator tries to use foreignization to deal with these elements, he will risk a word-for-word translation, which is called over-foreignization. While a translator mainly adopt a foreignizing method, he is supposed to use domestication where necessary and only in this way can he get a good translation. Translating poetry is a tough and fascinating job. Therefore, the translation of CCP as a broad subject demands urgently more careful and contributive research from more extensive perspectives. The present essay tries to explore the translation of CCP from a cultural perspective in the hope that it will be of some help to the spread of Chinese culture in the world through the translation of CCP, and to a better fulfillment of the duty of a translator as an ambassador of cultural exchange.

\section{REFERENCES}

[1] Liu Chongde. (1991). Ten Lecutures on Literary Translation. Beijing, China Translation \& Publishing Corporation.

[2] Newmark, Perter. (2001). A Textbook of Translation. Shanghai: Shanghai Foreign Language Education Press.

[3] Nida,Eugene A.\& Charles R. Taber. (2004). The Theory and Practice of Translation. Shanghai: Shanghai Foreign Language Education Press.

[4] Shuttleworth, Mark \& Moira Cowie. (2004). Dictionary of translation studies. Shanghai: Shanghai Foreign Language Education Press.

[5] Venuti Lawrence. (2004). The Translator's Invisibility. Shanghai: Shanghai Foreign Language Education Press.

[6] Zhang Junfeng. (2004). Milky way and "Niu Nai Lu", in Journal Of Tianjin Foreign Studies University11.6, 8-14.

Hongwei Ye was born in Jiangxi, China in 1978. He received his MA degree in English language and literature from Shanghai University, China in 2006.

$\mathrm{He}$ is currently a lecturer in the School of Fundamental Studies, Shanghai University of Engineering Science, Shanghai, China. His research interests include English language teaching, translation theory and practice. He is a member of Shanghai Science and Technology Translation Society. 